Research Article

\title{
Microannulus Formation Mechanism at the Cementing Interface of a Thermal Recovery Well during Cyclic Steam Injection
}

\author{
JiWei Wu, ${ }^{1}$ XueGang Wang, ${ }^{1}$ Lin Song, ${ }^{1}$ ShouMing Zhong, ${ }^{1}$ and WenFeng Yin $\mathbb{D}^{2}$ \\ ${ }^{1}$ Engineering Technology Research Institute of Xinjiang Oilfield Company, Karamay 834000, China \\ ${ }^{2}$ Petroleum Engineering School of Southwest Petroleum University, Chengdu 610500, China \\ Correspondence should be addressed to WenFeng Yin; yinwenfeng2010@163.com
}

Received 14 June 2019; Revised 5 January 2020; Accepted 23 January 2020; Published 22 February 2020

Academic Editor: Timo Saksala

Copyright (c) 2020 JiWei Wu et al. This is an open access article distributed under the Creative Commons Attribution License, which permits unrestricted use, distribution, and reproduction in any medium, provided the original work is properly cited.

\begin{abstract}
During the thermal recovery of heavy oil when using cyclic steam injection technology, a microannulus tends to form at the cementing interface subjected to high temperature and pressure during steam injection, and large temperature and pressure differences after injection can lead to wellbore integrity failure. In this study, a thermomechanical coupled finite element casingcement-formation model of a thermal recovery wellbore is established. The deformation of the wellbore during both the steam injection stage and the steam shutdown stage is analyzed. The microannulus formation mechanism at the cementing interface of the wellbore is studied. During steam injection, under the large thermomechanical coupling load, the wellbore generates a high stress that leads to elastic-plastic deformation. In the steam shutdown stage, with the load on the wellbore decreasing, elastic deformation recovers mostly, while plastic deformation continues. If the plastic deformation is large enough, a microannulus will form at the cementing interface. Increasing the elastic moduli of the casing, cement, and the formation can enlarge their plastic deformation during steam injection. The increase of plastic deformation of the cement or formation can enlarge the microannulus of the casing-cement interface or the cement-formation interface correspondingly in the steam shutdown stage.
\end{abstract}

\section{Introduction}

Heavy oil geological reserves far exceed other conventional crude oil reserves. Heavy oil has great potential for exploitation. However, with its high density and high viscosity, heavy oil's flow resistance from the oil layer to the surface is very high. Therefore, it is difficult to use conventional recovery methods to exploit heavy oil reservoirs [1]. Thermal recovery technology, such as cyclic steam injection, steamflooding, and steam-assisted gravity drainage, using thermal energy to reduce the viscosity of heavy oil is an important heavy oil recovery technology [2]. The cyclic steam injection is widely used because of its success in reducing viscosity and its low cost. Cyclic steam injection technology includes three stages: steam injection, soaking, and production (see Figure 1). In this study, the soaking stage and production stage are combined as a steam shutdown stage. First, high-temperature steam is injected into the oil well to heat the oil layer near the wellbore. Second, steam injection is stopped and the well is shut down for a period of time, so that the heat of the steam can be fully transferred to the heavy oil layer to reduce the viscidity of the heavy oil. Third, the well is opened for production. According to the specific situation of each well, one cycle of the technology usually lasts six months to a year, and a well often undergoes multiple cycles of steam injection [3].

During the steam injection stage, the average steam temperature is $\sim 200^{\circ} \mathrm{C}$ (although it can be $>350^{\circ} \mathrm{C}$ ), and the injection pressure is $>6 \mathrm{MPa}$ [4]. Thermal stress and mechanical stress are produced in the wellbore under the combined action of high temperature and high pressure. During the steam shutdown stage, the temperature and 


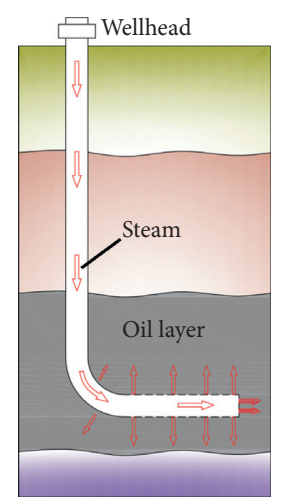

(a)

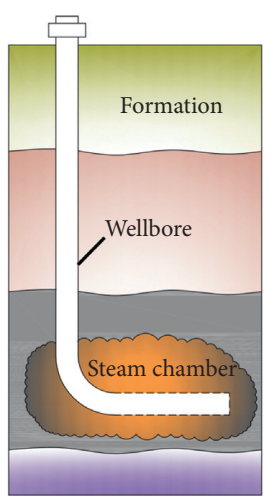

(b)

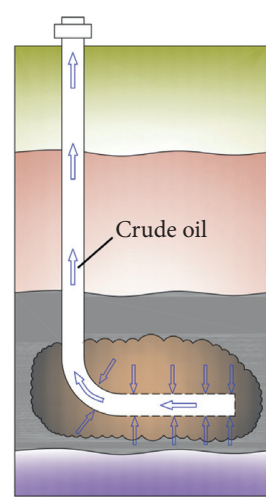

(c)

FIgure 1: Cyclic steam injection technology. (a) Injection. (b) Soaking. (c) Production.

pressure in the wellbore are significantly lower than those during the steam injection stage. The stress state and strain state of the wellbore also change dramatically. In a hightemperature, high-pressure, and cold-hot alternating environment, the integrity of the wellbore cement can easily fail. Channels of formation fluid will form in the cement, which leads to annular pressure or gas channeling and brings about significant economic losses and environmental damage. Therefore, studying the failure mechanism of cement is crucial to ensuring the integrity of the wellbore of thermal recovery wells.

Research by Ravi et al. shows that cement undergoes four main failure modes: radial cracking, shear failure, debonding of the casing-cement interface (inner debonding), and debonding of the cement-formation interface (outer interface) [5-9], as shown in Figure 2. Tabatabaei et al. introduced an experimental setup in conjunction with an analytical solution to measure the mixed-mode interfacial strength of cementitious materials at both casing-cement and rock-cement interfaces. They found that a uniform interfacial shear traction will produce a larger shear strength than a nonuniform shear traction [10]. Jackson, Goodwin, and other researchers have conducted laboratory simulation experiments for the failure of cement. Their results show that the change of temperature and pressure in the wellbore will not only cause breakage of cement but also produce a microannulus at the interface between the cement and the casing or between the cement and the formation, resulting in failure of wellbore integrity $[11,12]$.

On the basis of stress analysis of cement in a wellbore, many scholars have established the fracture strength criterion of cement [13-16]. However, research on the interface microannulus of cement is relatively sparse, and the microannulus formation mechanism at the cementing interface has not been well explained.

Research on the cementing interface microannulus has produced some important results. Xiao et al. established a casing-cement model under a uniform load based on the theory of thick-walled tubes. They supposed that elastic deformation of the casing and the cement could lead to the microannulus of the cementing interface and deduced a quantitative formula for calculating the microannulus after casing pressure testing [17]. Taleghani and Klimenko provided an analytical solution for the stress distribution and displacement along a cylindrical crack formed between the casing and the formation. They concluded not only that tensile bonding between the casing and the formation is important but also that the shear resistance along this interface could play an important role in containing the crack and providing resistance against further propagation [18]. Zhu et al. used zero-thickness pore pressure cohesive elements to simulate the casing-cement interface (CCI) and concluded that the failure mode of the cement sheath in the deep well is mainly interface separation and body damage caused by cement expansion and contraction or by pressure testing and well shut-in operations during hydraulic fracturing [19]. Based on the Mohr-Coulomb criterion, an elastic-plastic analysis model of the casing-cement-formation system was established by Chu. The process of pressure loading and unloading in the casing was analyzed using this model. The influence of cement plastic deformation on the formation of the microannulus in the cementing interface was considered, and the calculation formula for the size of the microannulus was given [20]. Because the solution of the plastic problem of the wellbore is complex, the finite element method is more economical and efficient for this problem. Fan et al. constructed a numerical model of a shale gas wellbore assemblage by using a step finite element method and analyzed the influence of in situ stress, formation elastic modulus, and cement properties on the microannulus of the cementing interface during the fracturing process [21].

In the process of cyclic steam injection, the wellbore of the thermal recovery well is subjected not only to the pressure of steam injection but also to the high temperature of steam. Under the action of thermomechanical coupling, the mechanism of microannulus formation in the cementing interface of thermal recovery wells is more complicated. In this study, an elastic-plastic model of the casing-cementformation system of thermal recovery well wellbores is established by using the finite element method. The deformation of the wellbore during the steam injection and steam shutdown stages is analyzed. The microannulus formation mechanism in the cementing interface in thermal recovery wells is discussed. The size of the microannulus at 

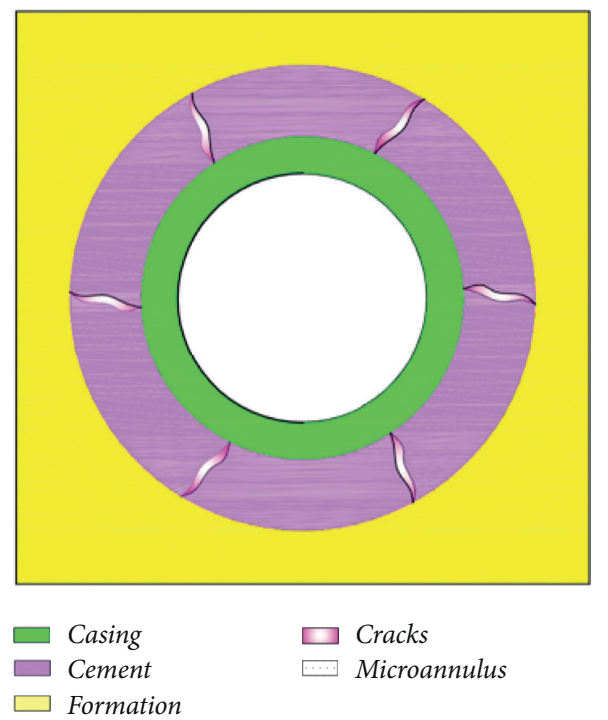

(a)
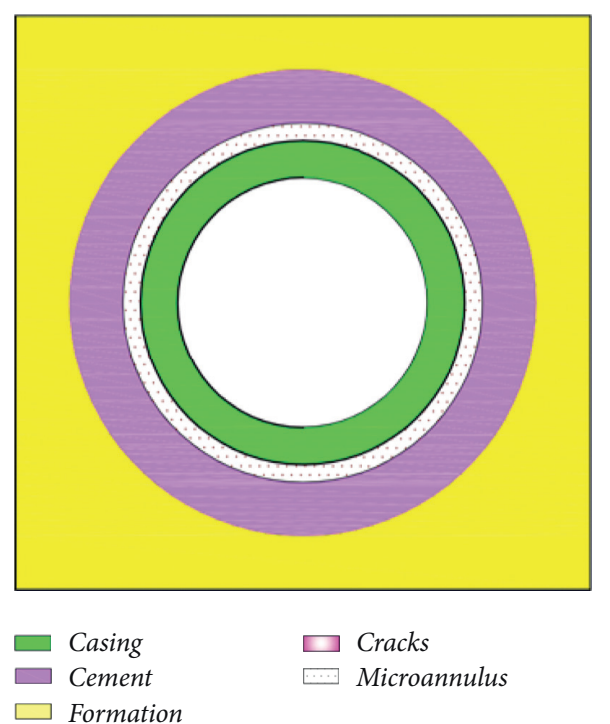

(c)

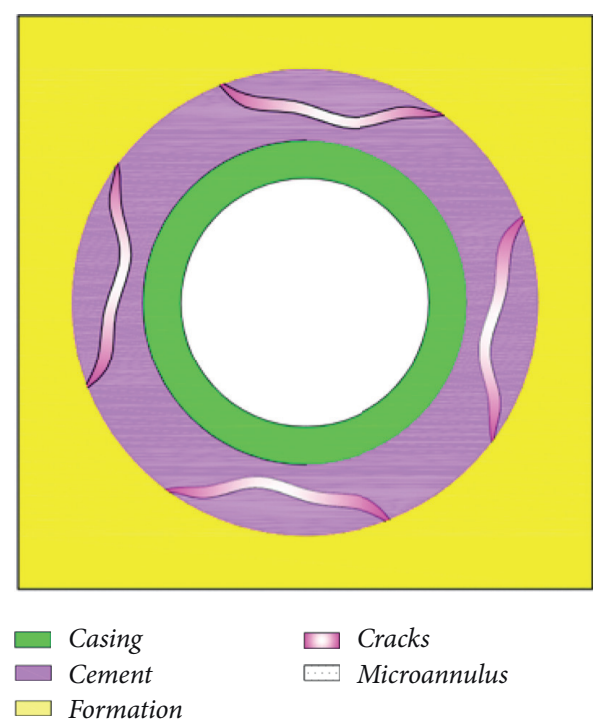

(b)

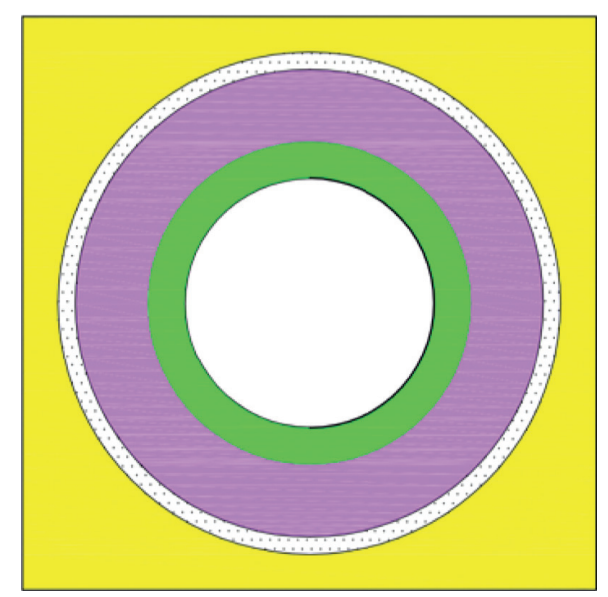

$\square$ Casing
$\square$ Cement
$\square$ Formation

$\square$ Cracks

… Microannulus

(d)

FIgURE 2: Failure modes of cement. (a) Radical cracks. (b) Shear failure. (c) Inner debonding. (d) Outer debonding.

the cementing interface is calculated, and the influence of the elastic moduli of the casing, cement, and the formation on the microannulus size is analyzed.

\section{Materials and Methods}

2.1. Analytical Method to Calculate Microannulus Size under Inner Pressure. During the steam injection stage, the casing, cement, and formation of the wellbore will produce high stress under high steam temperature and high injection pressure. The equivalent stress $\bar{\sigma}$, used to describe the wellbore stress state, is given by

$$
\bar{\sigma}=\sqrt{\frac{1}{2}\left[\left(\sigma_{x}-\sigma_{y}\right)^{2}+\left(\sigma_{y}-\sigma_{z}\right)^{2}+\left(\sigma_{z}-\sigma_{x}\right)^{2}+6\left(\tau_{x y}^{2}+\tau_{y z}^{2}+\tau_{z x}^{2}\right)\right]} .
$$

If the equivalent stresses of the casing, the cement, and the formation are lower than their material yield strengths, respectively, they only undergo elastic deformation. If the equivalent stresses exceed their material yield strengths, respectively, they will undergo plastic deformation. Elastic deformation can recover to the initial state after unloading, whereas plastic deformation is a permanent deformation that is considered as irrecoverable after unloading. Different types of deformations (plastic deformation or elastic deformation) may occur in the casing, the cement, and the formation during the steam injection stage, and the amounts of their deformation are different. The recoveries of deformation of the casing, the cement ring, and the formation are different during steam shutdown. Therefore, a microannulus may occur in the CCI or in the cement-formation interface. 
Solving plastic problems by analytic methods is very complicated. Therefore, in this study, the analytical method is used to calculate the microannulus size in the CCI for the case in which the wellbore is under only steam injection inner pressure, and the casing undergoes only elastic deformation, and the cement can have elastic-plastic deformation, as shown in Figure 3.

If the casing is under the action of borehole pressure $p_{i}$ and cement inner wall pressure $p_{1}$, according to Lame's formula, the radial displacement of the casing outer wall is [22]

$$
u_{\text {so }}=\frac{1+v_{1}}{E_{1}} \frac{2\left(1-v_{1}\right) r_{i}^{2} r_{1}}{r_{1}^{2}-r_{i}^{2}} p_{i}-\frac{1+v_{1}}{E_{1}} \frac{r_{i}^{2} r_{1}+\left(1-2 v_{1}\right) r_{1}^{3}}{r_{1}^{2}-r_{i}^{2}} p_{1} \text {. }
$$

If the pressure on the inner wall of the elastic zone of the cement is $p_{p}$ and the pressure on the outer wall of the elastic zone of the cement is $p_{2}$, the radial displacement of the inner wall of the elastic zone of the cement is

$$
u_{\mathrm{ci}}=\frac{1+v_{2}}{E_{2}} \frac{r_{p} r_{2}^{2}+\left(1-2 v_{2}\right) r_{p}^{3}}{r_{2}^{2}-r_{p}^{2}} p_{p}-\frac{1+v_{2}}{E_{2}} \frac{2\left(1-2 v_{2}\right) r_{p} r_{2}^{2}}{r_{2}^{2}-r_{p}^{2}} p_{2} \text {. }
$$

During the injection stage, let the pressure on the inner wall of the cement be $p_{1 m}$ and the pressure on the outer wall of the cement be $p_{2 m}$. During the steam shutdown stage, let the pressure on the inner wall of the casing be $p_{\text {in }}$, the pressure on the outer wall of the casing be $p_{1 n}$, the pressure on the inner wall of the cement be $p_{1 n}$, and the pressure on the outer wall of the cement be $p_{2 n}$. Then, according to equation (2), the radial displacement $u_{\text {son }}$ at the outer wall of the casing in during the steam shutdown stage is

$$
u_{\text {son }}=\frac{1+v_{1}}{E_{1}} \frac{2\left(1-v_{1}\right) r_{i}^{2} r_{1}}{r_{1}^{2}-r_{i}^{2}} p_{\text {in }}-\frac{1+v_{1}}{E_{1}} \frac{r_{i}^{2} r_{1}+\left(1-2 v_{1}\right) r_{1}^{3}}{r_{1}^{2}-r_{i}^{2}} p_{1 n} \text {. }
$$

The radial displacement of the inner wall of the cement $u_{\text {cin }}$ is the sum of the deformation $u_{\text {cpim }}$ (the deformation of the plastic zone boundary of the cement) generated during the steam injection stage and the elastic deformation change of the inner wall of the cement $u_{\text {cir }}$ during the steam shutdown stage, which can be obtained from equation (3) as

$$
\begin{aligned}
u_{\text {cin }}= & u_{\text {cpim }}+\frac{1+v_{2}}{E_{2}} \frac{r_{1} r_{2}^{2}+\left(1-2 v_{2}\right) r_{1}^{3}}{r_{2}^{2}-r_{p}^{2}}\left(p_{1 n}-p_{1 m}\right) \\
& -\frac{1+v_{2}}{E_{2}} \frac{2\left(1-v_{2}\right) r_{1} r_{2}^{2}}{r_{2}^{2}-r_{1}^{2}}\left(p_{2 n}-p_{2 m}\right) .
\end{aligned}
$$

During the steam shutdown stage, if the microannulus is generated in the CCI, that is, the interface between the casing and the cement is separated, the pressure on the outer wall of the casing and the inner wall of the cement will both become zero. At this time, according to equation (4), the radial displacement of the outer wall of the casing is

$$
u_{\text {son }}=\frac{1+v_{1}}{E_{1}} \frac{2\left(1-v_{1}\right) r_{i}^{2} r_{1}}{r_{1}^{2}-r_{i}^{2}} p_{\text {in }} .
$$

According to equation (5), the radial displacement of inner wall of cement is

$$
\begin{aligned}
u_{\text {cin }}= & u_{\text {cpim }}+\frac{1+v_{2}}{E_{2}} \frac{r_{1} r_{2}^{2}+\left(1-2 v_{2}\right) r_{1}^{3}}{r_{2}^{2}-r_{p}^{2}}\left(-p_{1 m}\right) \\
& -\frac{1+v_{2}}{E_{2}} \frac{2\left(1-v_{2}\right) r_{1} r_{2}^{2}}{r_{2}^{2}-r_{1}^{2}}\left(p_{2 n}-p_{2 m}\right) .
\end{aligned}
$$

The size of the microannulus in the CCI, $d_{n}$, is equal to the difference between the displacement of the inner wall of the cement $u_{\text {cin }}$ and the displacement of the outer wall of the casing $u_{\text {son }}$ during the steam shutdown stage [20]:

$$
d_{n}=u_{\text {cin }}-u_{\text {son }} .
$$

In the process of cyclic steam injection in thermal recovery wells, the wellbore is affected not only by steam injection pressure but also by the high steam temperature; elastic-plastic deformation occurs not only in the cement but also in the casing and the formation. Therefore, the microannulus formation mechanism in the cementing interface of the wellbore in thermal recovery wells is more complex. In this study, the finite element method is used to analyze the microannulus formation mechanism in the cementing interface.

\subsection{Finite Element Method to Calculate Microannulus Size} under Thermomechanical Coupling. A finite element model of thermal recovery wellbores was established by using ANSYS software, which was used to investigate the microannulus formation mechanism at the cementing interface by analyzing the temperature field and the deformation of the wellbore during the steam injection stage and steam shutdown stage. The model, consisting of casing, cement, and formation, was based on a cross section of the wellbore perpendicular to the borehole axis. Because the cross section of the wellbore is geometrically symmetrical and the load of the model is symmetrical, only $1 / 4$ of the cross section was used in the finite element analysis model in Figure 4 . The model was a two-dimensional plane strain model; its geometric parameters are given in Table 1 .

Cement exhibits elastic-plastic behavior under formation confining pressure [23]. According to the actual confining pressure of thermal recovery wells in situ, the stressstrain curve of cement stone under $9 \mathrm{MPa}$ of confining pressure was measured by using a triaxial test, as shown in Figure 5. As can be seen from the figure, the yield strength of the cement stone under $9 \mathrm{MPa}$ of confining pressure is $18 \mathrm{MPa}$. Under confining pressure, the formation behaves as elastic-plastic cement stone. The material parameters of the casing, the cement, and the formation are given in Table 2 based on literature values $[24,25]$.

The boundary conditions of the finite element model are as follows: (1) The displacement symmetry constraints are applied on the $0^{\circ}$ and $90^{\circ}$ boundaries of the $1 / 4$ model section. (2) Contact pairs are established between the casing and the cement and the cement and the formation, respectively. (3) The maximum and minimum horizontal in 


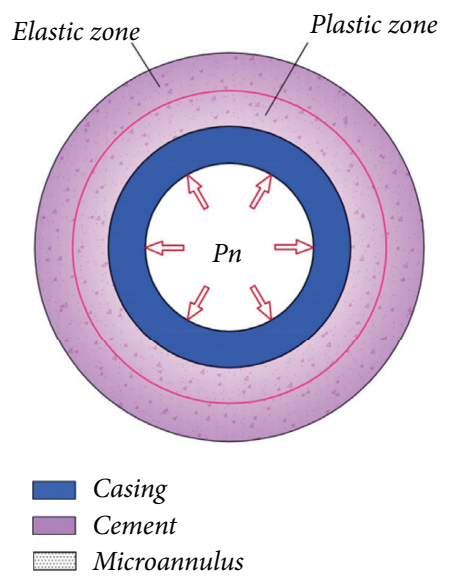

(a)

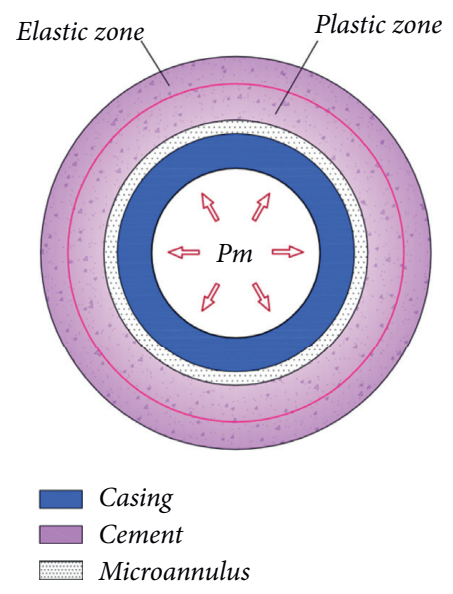

(b)

Figure 3: Formation of microannulus in casing-cement interface under inner pressure. (a) Injection. (b) After injection.

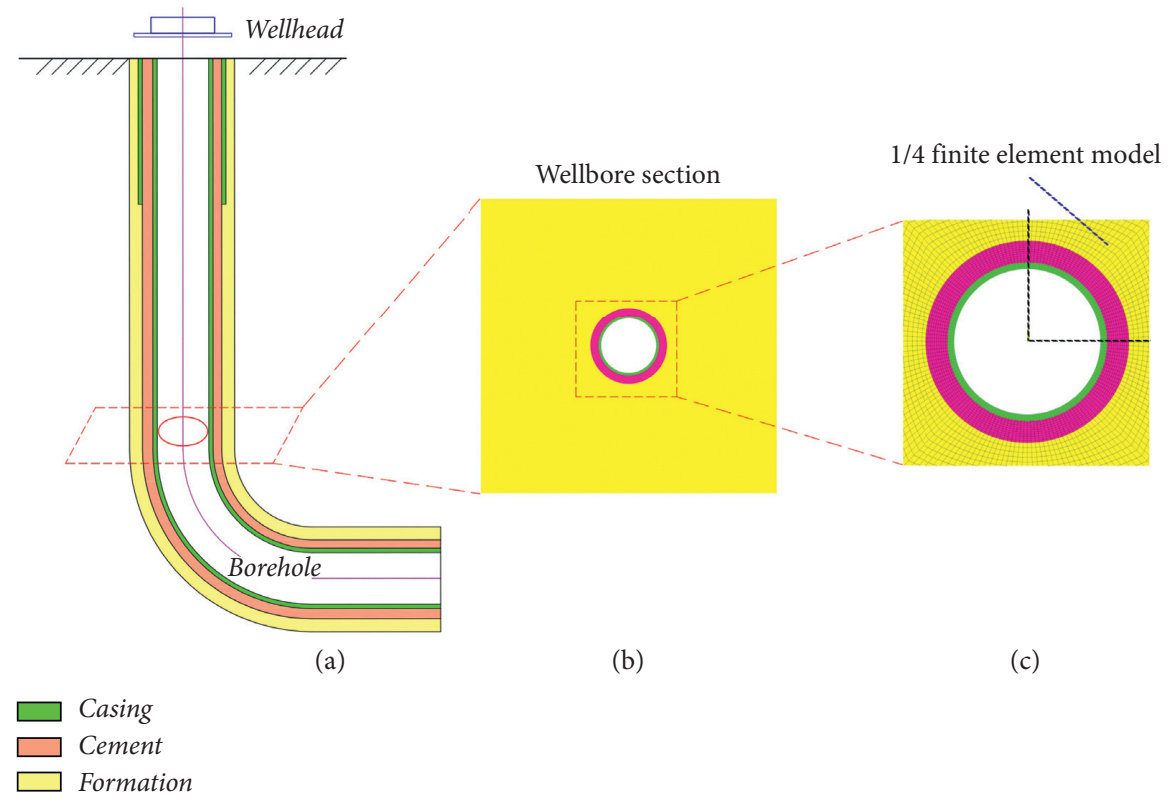

Figure 4: Finite element model of a thermal recovery wellbore.

TABLe 1: Geometric dimensions of finite element models.

Inner diameter of casing Outer diameter of casing $\quad$ Inner diameter of cement Outer diameter of cement Formation section size

$224.5 \mathrm{~mm} \quad 244.5 \mathrm{~mm} \quad 244.5 \mathrm{~mm} \quad 311.2 \mathrm{~mm} \quad 2000 \times 2000 \mathrm{~mm}$

situ stresses are applied to the outer boundary of the formation.

The loading of the finite element model is as follows: to simulate the steam injection stage and steam shutdown stage of the cyclic steam injection, two analysis steps were adopted. In the first loading step, the steam temperature and the injection pressure during the steam injection stage were applied to the inner surface of the casing. In the second loading step, the crude oil temperature and the crude oil lifting pressure during the steam shutdown stage were applied to the inner surface of the casing.

Thermal diffusion was considered to be caused only by the heat conduction of the casing-cement-formation system. The boundary conditions and loading conditions of the thermomechanical coupled finite element model of the casing-cement-formation are shown in Figure 6. 


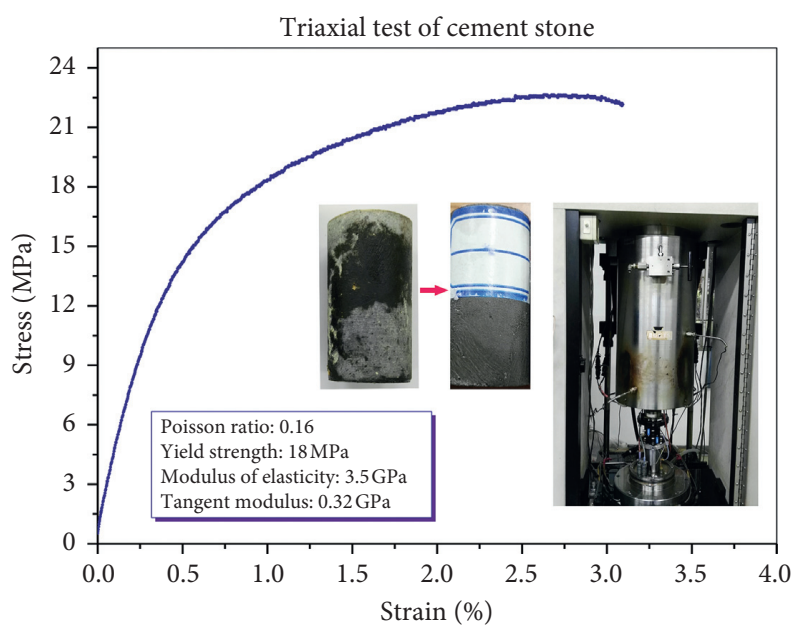

Figure 5: Triaxial test results for cement stone.

TABle 2: Material parameters of casing, cement and formation.

\begin{tabular}{|c|c|c|c|c|c|c|}
\hline Materials & Modulus of elasticity (GPa) & $\begin{array}{c}\text { Tangent } \\
\text { modulus (GPa) }\end{array}$ & Poisson ratio & $\begin{array}{l}\text { Coefficient of thermal } \\
\text { expansion }\left(10^{-6} \cdot{ }^{\circ} \mathrm{C}^{-1}\right)\end{array}$ & $\begin{array}{l}\text { Thermal conductivity } \\
\left(\mathrm{W} \cdot \mathrm{m}^{-1} \cdot{ }^{\circ} \mathrm{C}^{-1}\right)\end{array}$ & $\begin{array}{l}\text { Yield strength } \\
(\mathrm{MPa})\end{array}$ \\
\hline Casing & Vary & 61 & 0.3 & 9.6 & 45 & 621 \\
\hline Cement & Vary & 3.2 & 0.16 & 7.5 & 0.9 & 18 \\
\hline Formation & Vary & 3.2 & 0.2 & 7.5 & 2.2 & 22 \\
\hline
\end{tabular}

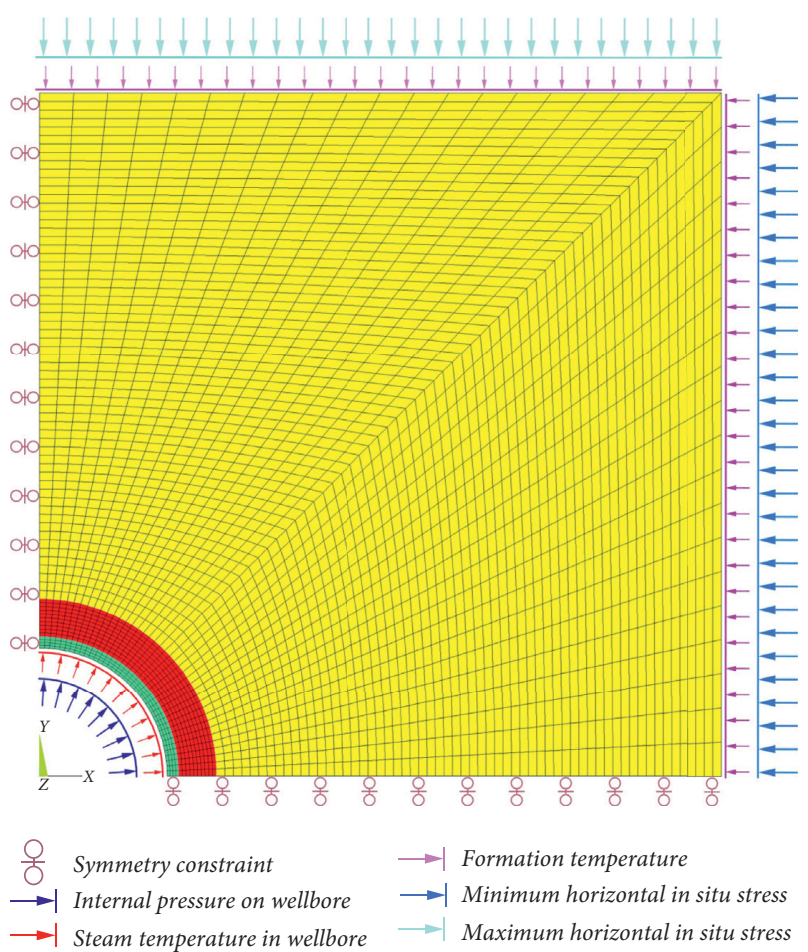

FIGURE 6: The boundary conditions and loading conditions of the finite element model.

\section{Results and Discussion}

3.1. Temperature Field of the Casing-Cement-Formation System. During the steam injection stage, with the wellbore temperature rising, thermal expansion deformation of the casing, the cement, and the formation occurs, and the formation exerts a certain constraint on the expansion deformation; thus, thermal stress in the casing-cement-formation system and elastic-plastic deformation occur correspondingly. Therefore, the temperature field of the wellbore is the basis of thermal stress and deformation analysis.

The temperatures of steam $\left(350^{\circ} \mathrm{C}\right)$ and crude oil $\left(40^{\circ} \mathrm{C}\right)$ were applied to the inner wall of the casing in the first and second loading steps, respectively. In both loading steps, the initial temperature of the formation $\left(25^{\circ} \mathrm{C}\right)$ was applied to the boundary of the formation. A steady-state heat transfer analysis of the wellbore was performed, and the temperature field distributions of the wellbore during the steam injection and the steam shutdown stages were obtained as shown in Figure 7.

With the increase of the distance from the center of the borehole, the temperature decreases from $250^{\circ} \mathrm{C}$ to $40^{\circ} \mathrm{C}$ of the inner borehole to $25^{\circ} \mathrm{C}$ of the far formation. The average temperature of the near-borehole area during the steam injection stage is much higher than that during the steam shutdown stage. Therefore, this large temperature difference can lead to a large thermal stress in the near-borehole area during the steam injection stage.

3.2. Microannulus Caused by the Elastic-Plastic Deformation of Cement. If only elastic deformation occurred in the casing, the cement, and the formation during the steam injection stage, it would be recovered during the steam shutdown stage. Therefore, a microannulus will not form in the cementing interface, as shown in Figures 8.A1, 8.B1, and 8.C1. 


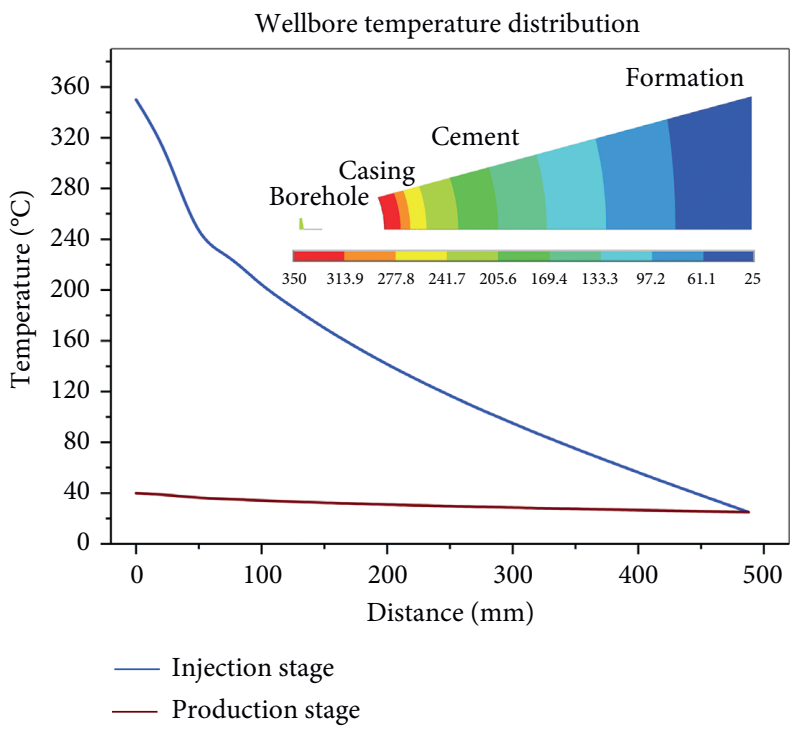

Figure 7: Wellbore temperature field distribution.
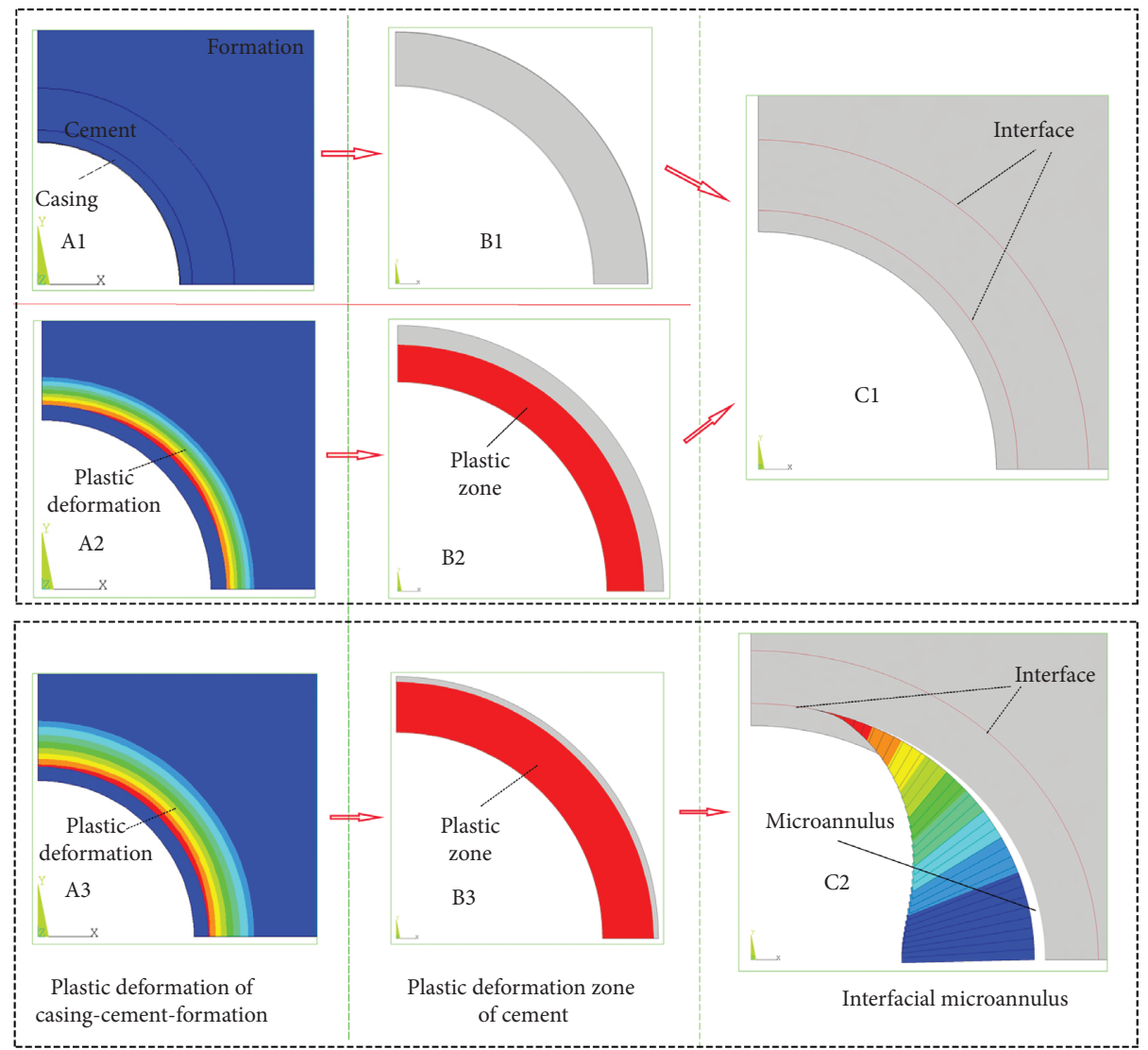

Figure 8: Microannulus caused by elastic-plastic deformation of cement.

If elastic deformation occurred in the casing and formation while elastic-plastic deformation occurred in the cement during the steam injection stage, whether or not a microannulus will form in the cementing interface during the steam shutdown stage depends on the plastic deformation properties of cement. If the plastic deformation of cement is small, there will be no microannulus at the cementing interface, as shown in Figures 8.A2, 8.B2, and 8.C1, whereas if the plastic deformation of cement is large, a microannulus will form, as shown in Figures 8.A3, 8.B3, and 8.C2. The reason for this difference is as follows: elastic deformation of the wellbore during the steam injection stage 
will not be fully recovered because of the temperature and internal pressure load in the wellbore during the steam shutdown stage. When the plastic deformation of the cement is less than the elastic deformation of the casing, which has not been fully restored, there will be no microannulus in the CCI. When the plastic deformation of the cement is larger than the elastic deformation of the casing, which has not been fully restored, the microannulus will form in the CCI. As the cement expanded from the near-casing side to the near-formation side plastically with the increase of borehole load, the microannulus in the cementing interface first appeared at the cement-casing interface.

\subsection{Microannulus Caused by Elastic-Plastic Deformation of} the Casing, the Cement, and the Formation. With the increase of steam temperature and injection pressure during the steam injection stage, plastic deformation can occur in the casing, the cement, and the formation. Whether or not a microannulus forms at the cementing interface depends on whether plastic deformation occurs in the cement and in the formation and the amounts of plastic deformation.

As shown in Figures 9.D1 and 9.E1, for plastic deformation occurring in both the casing and the cement, if the amount of plastic deformation of the cement is small, a microannulus will not form in the CCI. As shown in Figures 9.D2 and 9.E2, when the plastic deformation of the cement is large enough, a microannulus will form in the CCI. Because plastic deformation did not occur in the formation, the microannulus will not form in the cement-formation interface. As shown in Figures 9.D3 and 9.E3, the microannulus formed in the cement-formation interface when plastic deformation occurred in the formation and the amount of deformation was large enough.

The reason for the microannulus forming in the cementing interface in the cyclic steam injection process is as follows: during the steam injection stage, the casing, the cement, and the formation of the wellbore will all experience relatively high stress under the action of thermomechanical coupling. If the equivalent stress in the casing, the cement, and the formation exceeds their material yield limit, they will undergo plastic deformation. While plastic deformation occurs, elastic deformation also occurs in the casing, the cement, and the formation. During the steam shutdown stage, the plastic deformation of the casing, the cement, and the formation cannot be recovered, but the elastic deformation can be partially recovered. If the plastic deformation of the cement or the formation between the CCI and the cement-formation interface is too large to be offset by the elastic deformation during the steam shutdown stage, a microannulus will occur in the cementing interface.

\subsection{Factors Influencing the Microannulus in the Cementing Interface}

3.4.1. Elastic Modulus of Cement. We studied the influence of the elastic modulus of cement in the range of 3.5-15.5 GPa on the microannulus size in the cementing interface. As shown in Figure 10, when the elastic modulus of cement was
3.5 GPa, there was no plastic deformation and no microannulus formed. With the increase of elastic modulus, a microannulus of increasing size in the cement-casing interface forms. This is because, under the same conditions, the greater the elastic modulus of cement, the greater the cement stress and the greater the plastic deformation.

3.4.2. Elastic Modulus of the Casing. We next studied the influence of the elastic modulus of the casing in the range of 180-220 GPa on the microannulus size in the cementing interface. As shown in Figures 11.F1, 11.G1, 11.F2, 11.G2, and 12, when the elastic modulus of the casing was 180 and $190 \mathrm{GPa}$, respectively, only elastic deformation occurred in the casing and plastic deformation occurred in the cement. When $E=180 \mathrm{GPa}$, the maximum plastic deformation of cement was $1.6 \times 10^{-4}$, and there was no microannulus in the cementing interface. When $E=190 \mathrm{GPa}$, the maximum plastic deformation of cement was $1.9 \times 10^{-4}$, which was larger than that when $E=180 \mathrm{GPa}$, and the microannulus formed in the cement-casing interface. As shown in Figures 11.F3, 11.G3, 11.F4, 11.G4, and 12, when the elastic modulus of the casing was 200 and $210 \mathrm{GPa}$, respectively, plastic deformation occurred in both the casing and the cement, and the maximum plastic deformation of cement $>1.9 \times 10^{-4}$. Therefore, the microannulus formed in the CCI.

As shown in Figure 12, with the increase of elastic modulus of the casing, the maximum plastic deformation of the casing and the cement both increased, and the microannulus size in the CCI increased. The increasing trend in microannulus size was similar to that of the plastic deformation of the cement. The rate of increase was higher in the range of $190-210 \mathrm{GPa}$ than that in the range of $210-220 \mathrm{GPa}$, because the increase of plastic deformation of casing counteracted part of the plastic deformation of the cement.

3.4.3. Elastic Modulus of the Formation. We then studied the influence on the microannulus in the cement-formation interface of the elastic modulus of the formation in the range of $15-35 \mathrm{GPa}$ under the condition in which plastic deformation occurred in the casing and in the cement and the microannulus formed in the CCI. As shown in Figures 13 and 14, when the elastic modulus of the formation was 15 and $25 \mathrm{GPa}$, respectively, no microannulus formed in the cement-formation interface. When $E=15 \mathrm{GPa}$, the formation underwent no plastic deformation, while when $E=25 \mathrm{GPa}$, the formation did undergo plastic deformation, which indicates that the microannulus forming in the cement-formation interface does not directly depend on whether plastic deformation occurs in the formation. When the elastic modulus of the formation was $30 \mathrm{GPa}$, the plastic deformation of the formation was $5.2 \times 10^{-4}$, which was larger than that when $E=25 \mathrm{GPa}$, which was $3.6 \times 10^{-4}$, and the microannulus formed in the cement-formation interface. This indicates that the microannulus in the cement-formation interface is related to the amount of plastic deformation of the formation.

As shown in Figure 14, with the increase of the elastic modulus of the formation, plastic deformations of both the 


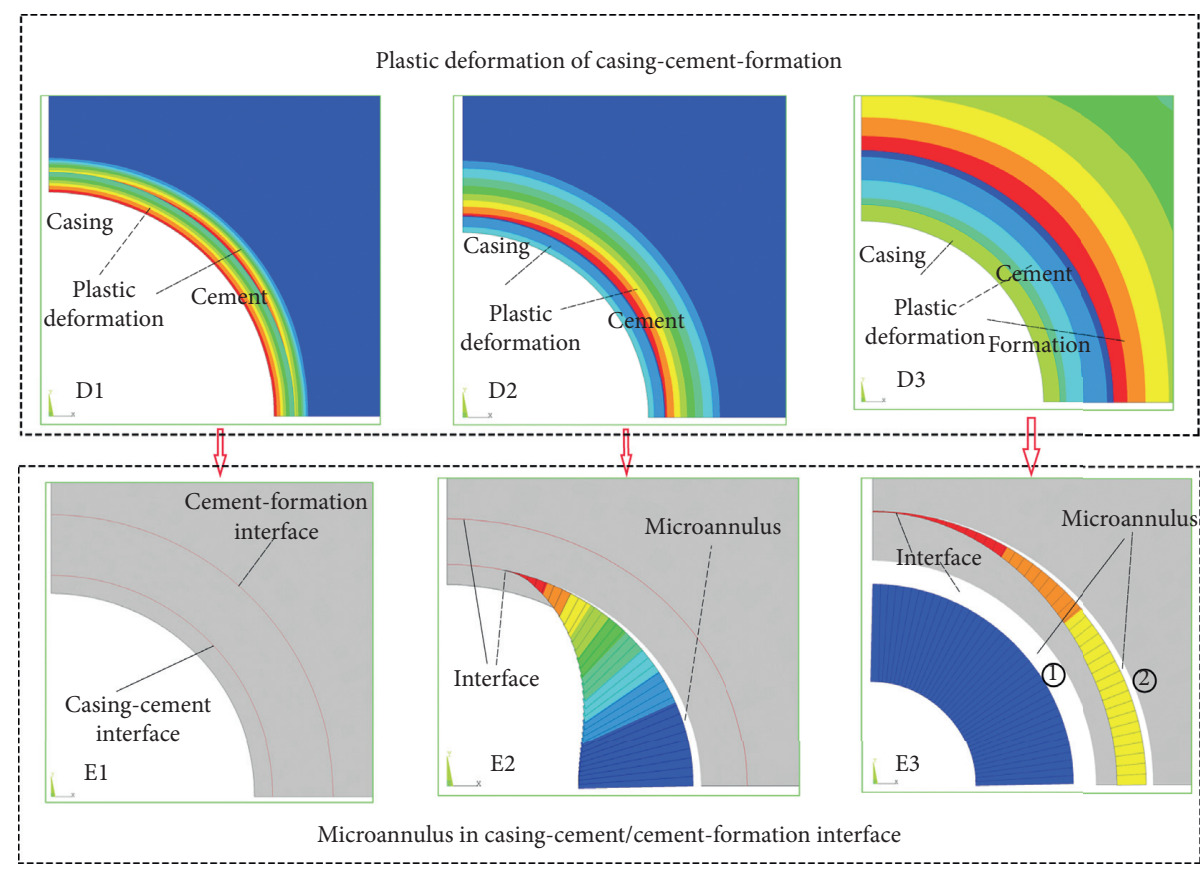

Figure 9: Microannulus caused by elastic-plastic deformation of the casing, the cement, and the formation.

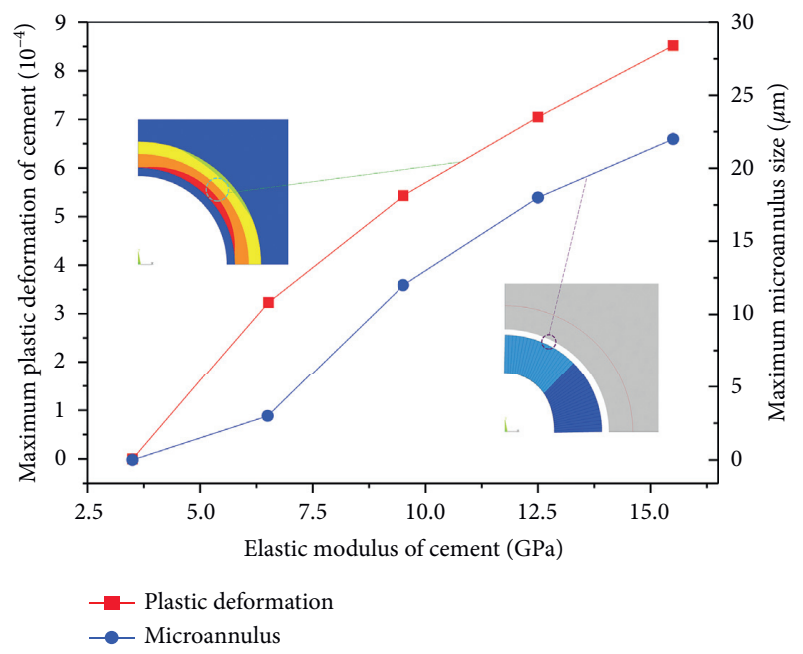

Figure 10: Influence of the elastic modulus of the cement on microannulus size.

formation and the casing increase, while plastic deformation of the cement decreased. Therefore, the increase of plastic deformation of the formation is greatly influenced by the increase of the formation elastic modulus, whereas the plastic deformation of the casing and cement changed little with the increase of the formation elastic modulus.

The microannulus size of the CCI increased first and then tended to be stable with the increase of the elastic modulus of the formation. This trend results from the microannulus size of the CCI mainly depending on the plastic deformation of the cement. When the plastic deformation of the cement tended to be stable, the microannulus size of the CCI tended to be stable.

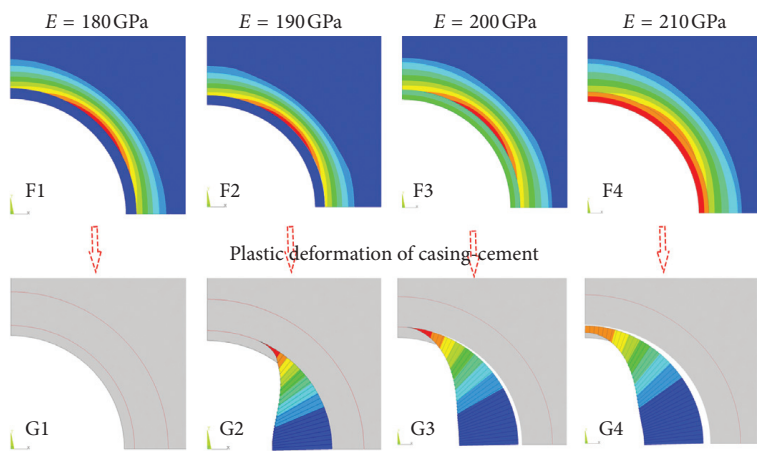

FIGURE 11: Plastic deformation and microannulus with different casing elastic moduli.

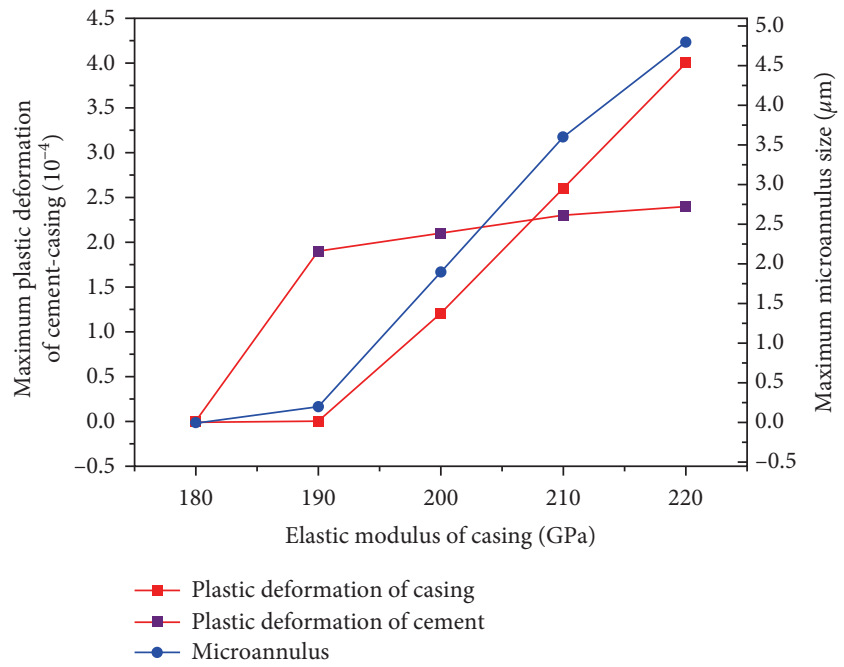

FIgURE 12: Influence of the elastic modulus of the casing on microannulus size. 


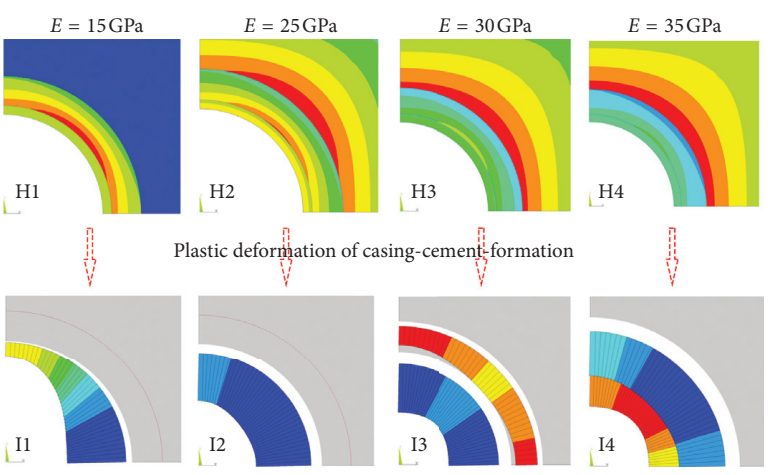

FIGURE 13: Plastic deformation and microannulus with different formation elastic moduli.

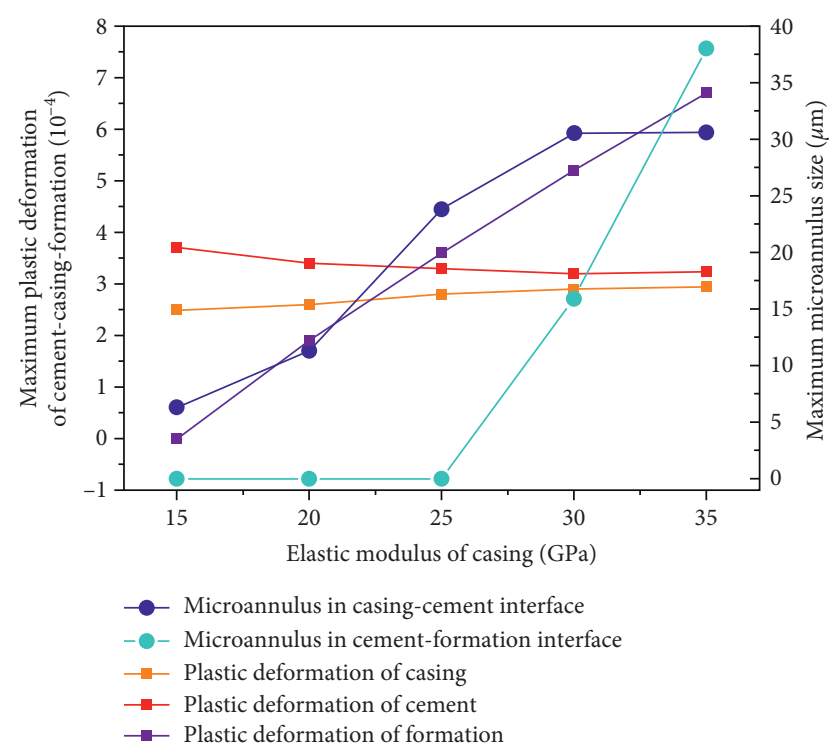

FIGURE 14: Influence of the elastic modulus of the formation on microannulus size.

The microannulus size of the cement-formation interface increased with the increase of the elastic modulus of the formation. The variation trend is greatly influenced by that of the plastic deformation of the formation, indicating that the microannulus in the cement-formation interface is related to the amount of plastic deformation of the formation. The plastic deformation of the formation mainly determines the microannulus size of the cement-formation interface.

\section{Conclusions}

(1) During the steam injection stage, the increasing pressure and temperature produce internal stress in the casing, the cement, and the formation under the action of thermomechanical coupling. When the equivalent internal stress exceeds the material yield limit, plastic deformation will occur in the casing, the cement, and the formation. During the steam shutdown stage, the decreasing pressure and temperature decrease the stress in the casing, the cement, and the formation. The elastic deformation can recover, but plastic deformation cannot recover. Therefore, the microannulus may form in the cementing interface, where plastic deformation of the casing, the cement, and the formation cannot recover.

(2) During the steam injection stage, if the casing, the cement, and the formation undergo only elastic deformation, there will be no microannulus in the cementing interface after injection. If the casing, the cement, and the formation undergo elastic-plastic deformation during the steam injection stage, whether or not the microannulus forms in the cementing interface after injection mainly depends on the amount of plastic deformation of the cement or the formation during the steam injection stage. If the plastic deformation of the cement or the formation is small, there will be no microannulus in the cementing interface after injection. If the plastic deformation of the cement or the formation reaches a critical value, the microannulus will form in the cementing interface.

(3) With the increase of the elastic modulus of the cement, plastic deformation of the cement increases during the steam injection stage, and the microannulus size of the cement-casing interface increases after injection. With the increase of the elastic modulus of the casing, plastic deformations of the casing and the cement increase during the steam injection stage, and the size of the microannulus in the cement-casing interface increases after injection. With the increase of plastic deformation of the casing, the growth rate of the microannulus size in the cement-casing interface slows. With the increase of the elastic modulus of the formation, plastic deformation of the formation increases, while plastic deformations of the casing and the cement change little. The microannulus size of the CCI increases first and then tends to be stable. The microannulus size of the cement-formation interface increases with the increase of plastic deformation of the formation.

\section{Data Availability}

The data used to support the findings of this study are included within the article.

\section{Conflicts of Interest}

The authors declare that they have no conflicts of interest.

\section{Acknowledgments}

This work was supported by China National Science and Technology Major Project (Project no. 2017ZX05070).

\section{References}

[1] A. Shafiei, M. Ahmadi, M. Dusseault, A. Elkamel, S. Zendehboudi, and I. Chatzis, "Data analytics techniques for 
performance prediction of steamflooding in naturally fractured carbonate reservoirs," Energies, vol. 11, no. 2, p. 292, 2018.

[2] S. Guo, Y. Bu, and X. Yan, "Cement integrity under two different formation conditions in steam stimulation well," in Proceedings of the Twenty-Fifth International Ocean and Polar Engineering Conference, Kona, HI, USA, June 2015.

[3] M. Abimbola, F. Khan, and N. Khakzad, "Risk-based safety analysis of well integrity operations," Safety Science, vol. 84, pp. 149-160, 2016.

[4] G. D. Dean and R. S. Torres, "Novel cement system for improved zonal isolation in steam injection wells," in Proceedings of the SPE International Thermal Operations and Heavy Oil Symposium and International Horizontal Well Technology Conference, Calgary, Alberta, Canada, November 2002.

[5] K. Ravi, M. Bosma, and O. Gastebled, "Improve the economics of oil and gas wells by reducing the risk of cement failure," in Proceedings of the IADC/SPE Drilling Conference, pp. 26-28, Dallas, TX, USA, February 2002.

[6] S. Peng, J. Fu, and J. Zhang, "Borehole casing failure analysis in unconsolidated formations: a case study," Journal of Petroleum Science and Engineering, vol. 59, no. 3-4, pp. 226-238, 2007.

[7] H. Xu, T. Ma, N. Peng, and B. Yang, "Influences of fracturing fluid injection on mechanical integrity of cement sheath under four failure modes," Energies, vol. 11, no. 12, p. 3534, 2018.

[8] Z. Yuan, C. Teodoriu, and J. Schubert, "Low cycle cement fatigue experimental study and the effect on HPHT well integrity," Journal of Petroleum Science and Engineering, vol. 105, pp. 84-90, 2013.

[9] A.-P. Bois, A. Garnier, G. Galdiolo, and J.-B. Laudet, "Use of a mechanistic model to forecast cement-sheath integrity," SPE Drilling \& Completion, vol. 27, no. 2, pp. 303-314, 2012.

[10] M. Tabatabaei, A. D. Taleghani, and N. Alem, "Measurement of mixed mode interfacial strengths with cementitious materials," Engineering Fracture Mechanics, 2019.

[11] P. B. Jackson and C. E. Murphey, "Effect of casing pressure on gas flow through a sheath of set cement," in Proceedings of the SPE/IADC Drilling Conference, pp. 22-25, Amsterdam, Netherlands, February 1993.

[12] K. J. Goodwin and R. J. Crook, "Cement sheath stress failure," SPE Drilling Engineering, vol. 7, no. 4, pp. 291-296, 1992.

[13] W. R. M. de Souza, N. Bouaanani, A. E. Martinelli, and U. T. Bezerra, "Numerical simulation of the thermomechanical behavior of cement in wells subjected to steam injection," Journal of Petroleum Science and Engineering, vol. 167, pp. 664-673, 2018.

[14] W. Wang and A. D. Taleghani, "Three-dimensional analysis of cement sheath integrity around Wellbores," Journal of Petroleum Science and Engineering, vol. 121, pp. 38-51, 2014.

[15] D. L. Bour, "Cyclic steam well design: a new approach to solve an old problem of cement failure in cyclic steam wells," in Proceedings of the SPE Western Regional Meeting, Irvine, CA, USA, March 2005.

[16] M. Fan, J. Li, and G. Liu, "New method to analyse the cement sheath integrity during the volume fracturing of shale gas," Energies, vol. 11, no. 4, p. 750, 2018.

[17] Y. Xiao, B. Zhou, M. Li et al., "The influence of casing pressure test on the sealing of cement rings," Journal of Xi'an Petroleum University, vol. 24, no. 3, pp. 31-34, 2009.

[18] A. D. Taleghani and D. Klimenko, "An analytical solution for microannulus cracks developed around a wellbore," Journal of
Energy Resources Technology, vol. 137, no. 6, Article ID 062901, 2015.

[19] H. Y. Zhu, J. G. Deng, J. Zhao, H. Zhao, H. L. Liu, and T. Wang, "Cementing failure of the casing-cement-rock interfaces during hydraulic fracturing," Computers and Concrete, vol. 14, no. 1, pp. 91-107, 2014.

[20] W. Chu, J. Shen, Y. Yang, Y. Li, and D. Gao, "Calculation of micro-annulus size in casing-cement sheath-formation system under continuous internal casing pressure change," $P e$ troleum Exploration and Development, vol. 42, no. 3, pp. 414-421, 2015.

[21] M. Fan, J. Li, G. Liu, and X. Chen, "Study on the mechanism of micro-annulus formation at cementing interface of shale gas backlog fracturing," Petroleum Machinery, vol. 46, no. 10, pp. 78-82, 2018.

[22] J. Li, M. Chen, G. Liu et al., "Elastic-plastic analysis of casingconcrete sheath-rock combination," Acta Petrolei Sinica, vol. 26, no. 6, pp. 99-103, 2005.

[23] Y. Zhang and J. Shao, "Constitutive model of cement-based materials in wide confining pressure range," Journal of Solid Mechanics, vol. 32, no. 3, pp. 293-298, 2011.

[24] J. De Andrade and S. Sangesland, "Cement sheath failure mechanisms: numerical estimates to design for long-term well integrity," Journal of Petroleum Science and Engineering, vol. 147, pp. 682-698, 2016.

[25] R. Gholami, B. Aadnoy, and N. Fakhari, "A thermo-poroelastic analytical approach to evaluate cement sheath integrity in deep vertical wells," Journal of Petroleum Science and Engineering, vol. 147, pp. 536-546, 2016. 